\title{
Review
}

\section{Heart regeneration using reprogramming technology}

\author{
By Masaki IEDA $* 1, * 2, * 3, \dagger$ \\ (Communicated by Hiroo ImURA, M.J.A.)
}

\begin{abstract}
Loss of terminally differentiated cardiomyocytes due to heart disease is irreversible and current therapeutic regimes are limited. Cell therapy using stem cell-derived cardiomyocytes is an attractive option to repair injured hearts. The discovery of direct reprogramming of fibroblasts into induced pluripotent stem cells (iPSCs) and successful differentiation of iPSCs into cardiomyocytes provided a revolutionary paradigm in heart regenerative research. During the past decades, significant advances in stem cell culture, differentiation and purification protocols, as well as in cell transplantation methodologies, have been achieved. On the other hand, recent studies demonstrated that a somatic cell could be converted into an alternative differentiated cell type without first becoming a stem cell by overexpression of lineage-specific factors. We found that functional cardiomyocytes can be directly induced from fibroblasts by a combination of three cardiac transcription factors, Gata4, Mef2c and Tbx5, in vitro and in vivo. I will review the perspectives of heart regeneration using reprogramming technology.
\end{abstract}

Keywords: heart, heart regeneration, iPS cell, induced cardiomyocyte, reprogramming

\section{Introduction}

Heart disease is a leading cause of death worldwide. As adult cardiomyocytes have little regenerative capacity following injury, their malfunction or loss due to heart disease may lead to lethal consequences. Heart transplantation is an established therapy for heart failure, but is limited due to the number of donor organs available. ${ }^{1)}$ Thus, new cardiac regeneration therapy is demanded, and cell replacement treatment might be an attractive option to repair injured myocardium. In particular, advances in stem cell research during the past decades have brought a tremendous amount of excitement about the possibility of using stem cells to repair damaged cardiac tissues. ${ }^{2)}$

\footnotetext{
*1 Department of Clinical and Molecular Cardiovascular Research, Keio University School of Medicine, Tokyo, Japan.

*2 Department of Cardiology, Keio University School of Medicine, Tokyo, Japan.

*3 JST, CREST, Tokyo, Japan.

$\dagger$ Correspondence should be addressed: M. Ieda, Department of Cardiology, Keio University School of Medicine, 35 Shinanomachi, Shinjuku-ku, Tokyo 160-8582, Japan (e-mail: mieda@z8.keio.jp).
}

Embryonic stem cells (ESCs) remain undifferentiated and propagate infinitely in culture, while maintaining their pluripotency to differentiate into all three embryonic germ layers and their derivatives, including cardiomyocytes. Therefore, it is possible to generate a large number of cardiomyocytes from differentiated cultures of ESCs. ${ }^{3)-5)}$ Moreover, with the recent discovery of induction of pluripotency with Yamanaka's four factors, researchers can make cardiomyocytes from patients' somatic cells through induced pluripotent stem cell (iPSC) generation. $\left.{ }^{6)}, 7\right)$ Recent findings demonstrated that human pluripotent stem cells (PSCs) can be efficiently differentiated into cardiomyocytes using small molecules and growth factors. ${ }^{8,9)}$ Moreover, to reduce the risk of tumor formation by contamination of residual PSCs, procedures involving cell sorting with specific cellsurface markers and a mitochondrial dye have been developed for cardiomyocyte enrichment. ${ }^{10)-12)}$ Electrical coupling of human PSC-derived cardiomyocytes and the suppression of arrhythmias in injured hearts has been reported in guinea-pig recently. ${ }^{13)}$ Thus, cell therapy using iPSC technology might be a potential regenerative strategy for patients with heart disease in the future. 
We and others recently reported that a somatic cell could be directly reprogrammed into an alternative differentiated cell type without first becoming a stem/progenitor cell. ${ }^{14)-18)}$ We found that a combination of three cardiac transcription factors, Gata4, Mef2c, and Tbx5, rapidly and efficiently induced cardiomyocyte-like cells (iCMs) from mouse cardiac fibroblasts. ${ }^{14)}$ The induced cardiomyocytes were similar to neonatal cardiomyocytes and could be useful as a source of cardiomyocytes for regenerative purpose. ${ }^{14)}$ More recently, we and others have demonstrated that direct gene transfer of cardiac reprogramming factors in mouse infarct hearts converted resident cardiac fibroblasts into cardiomyocyte-like cells. ${ }^{19)-21)}$ However, compared with the iPSC field, the direct lineage reprogramming has just emerged and more refinements and investigations will be necessary for future regenerative applications. In this article, I will review the ESC/iPSC-based cardiac regeneration and a new emerging technology, direct cardiac reprogramming.

\section{Generation of cardiomyocytes from pluripotent stem cells}

ESCs are undifferentiated, pluripotent and selfrenewing cells in appropriate culture conditions. In their differentiated state, they can give rise to cells of all three embryonic germ layers. In vitro ESC differentiation requires an initial step of forming three-dimensional aggregates called embryoid bodies (EBs). EBs mimic the development of the embryos and they can differentiate into a wide variety of cell types including cardiomyocytes. The development and gene expression profiles of ESC-derived cardiomyocytes correlate well with those of developing mammalian hearts, becoming mature with time. Thus, the most successful differentiation approaches of ESCs are those that recapitulate the regulatory pathways that control cardiac differentiation in the early embryo.9) Using cues from developmental biology, significant advances have been made in cardiac differentiation from mouse and human PSCs.

Findings from serial studies demonstrated that one of the earliest stages of differentiation, the induction of cardiac progenitor cells, can be monitored by the expression of cell surface markers, vascular endothelial growth factor receptor-2 (KDR/ Flk-1) and platelet-derived growth factor receptor (PDGFR)- $\alpha$, or by the expression of transcription factors, isl-1 and Nkx2.5, in the cells. ${ }^{22-24)}$ Stagespecific induction of mouse and human ESCs with chemically-defined media containing activin $\mathrm{A}$, bone morphogenetic protein-4, basic fibroblast growth factor, vascular endothelial growth factor and temporal modulation of canonical Wnt signaling results in generation of abundant KDR/PDGFR- $\alpha$ doublepositive cardiac progenitor cells which can efficiently differentiate into cardiomyocytes in vitro. ${ }^{9), 22)}$ On the other hand, mesp1 is one of the earliest transcription factors in cardiac progenitor cells and critical for heart development. ${ }^{25), 26)}$ Mesp1 overexpression in mouse ESCs activated cardiac transcriptional regulators, Gata4, Mef2c, Tbx5, myocardin, and Nkx2.5, and differentiated the ESCs into the cardiovascular lineage. ${ }^{27)}$ Further modifications of these strategies may enable induction of a large cardiac progenitor cell pool, which lead to generation of highly enriched cardiomyocytes (Fig. 1).

Generation of patient-specific cells for autologous transplantation should be pursued to avoid immune rejection of the transplanted cardiac grafts. Takahashi and Yamanaka discovered that four ESCenriched transcription factors, Oct4, Sox2, Klf4 and c-Myc, can reprogram mouse fibroblasts into ESClike cells, iPSCs, in 2006. ${ }^{7)}$ Just one year later, human iPSCs were generated by the same set of transcriptional factors, as well as another set of factors (Fig. 1). ${ }^{28), 29)}$ Although there has been some concern that human iPSCs are not identical to ESCs, iPS cells are very similar to human ESCs morphologically and they have been shown to differentiate into cell types of all three germ layers, as well as cardiomyocytes. ${ }^{29)}$ Initially, iPSCs were made from somatic cells by retroviral or lentiviral transduction of the required transcription factors. Transgenes are inserted randomly into the host genome by this method and may therefore disrupt normal gene expression. To avoid insertional mutagenesis, iPSCs were recently generated by transduction of the reprogramming factors without genome integration, using plasmids, mRNAs, proteins and removable transposons as well as Sendai viruses. ${ }^{30), 31)}$ Although there is variability among cell lines, iPSCs can be differentiated into cardiomyocytes with the same cardiac differentiation protocol originally developed for ESCs. Patientspecific iPSC-derived cardiomyocytes could be obtained for cell therapy in the future, thereby possibly avoiding the immune rejection problems. Moreover, iPSCs may offer the possibility of generating genecorrected, patient-specific cardiac cells from individuals who have genetic diseases. ${ }^{32}$ Appropriate evaluation of safe iPSC clones as a cell source for cardiomyocytes might be critical for future applications in heart regeneration therapy. ${ }^{33)}$ 


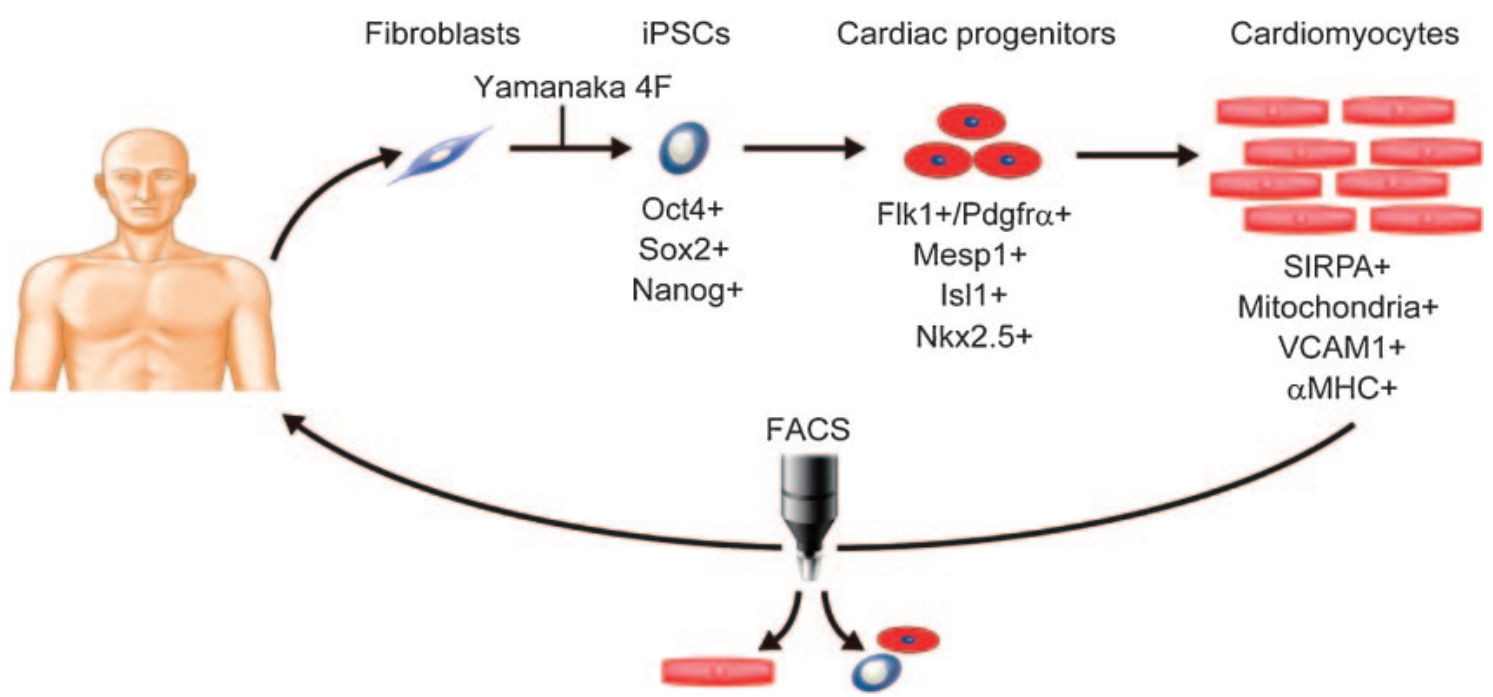

Fig. 1. Cardiac regenerative strategy through human iPS cell generation. Fibroblasts are obtained from patients, and reprogrammed into iPSCs by transduction of Yamanaka's 4 factors. The iPSCs differentiate into cardiac progenitors and cardiomyocytes, which express specific genes and markers. Pure cardiomyocytes can be sorted by FACS for cell treatment.

\section{Heart repair using pluripotent stem cell-derived cardiomyocytes}

As cardiomyocytes are terminally differentiated cells, myocardial tissue recovery after injury is particularly limited. The transplantation of cardiomyocytes derived from PSCs into the infarcted heart has been reported to improve cardiac function in animal models. ${ }^{3), 5)}$ Laflamme et al. reported an improvement in cardiac function 4 weeks after coronary artery ligation and injection of human ESC-derived cardiomyocytes in immunodeficient rats. $^{3)}$ In contrast, van Laake et al. reported that improvement of heart function was observed at 1 month but not at 3 months after myocardial infarction and injection of ESC-derived cardiomyocytes in mouse hearts. ${ }^{5)}$ The precise mechanisms mediating the beneficial effect of transplanted ESCderived cardiomyocytes are currently unclear, as the majority of the grafted cardiomyocytes disappeared gradually after direct injection of cells into the heart. 3),34) Thus, to enhance the effect of PSC-based cardiac repair, it is important to improve the survival of grafted cells. The administration of prosurvival factors with the grafted cells may improve the survival of transplanted PSC-derived cardiomyocytes. $^{3)}$ The formation of aggregates of PSC-derived cardiomyocytes through cell-cell adhesion may improve their survival in the heart through auto- and paracrine factors. ${ }^{11)}$ Recently, Shiba et al. reported that human ESC-derived cardiac grafts in injured hearts protected against arrhythmias and contracted synchronously with host muscle in guinea-pig hearts at least till 1 month. ${ }^{13)}$ Injured hearts with cardiac grafts showed improved mechanical function and a significantly reduced incidence of both spontaneous and induced ventricular tachycardia. It would be necessary to carry out safety and efficacy studies with longer follow-up durations in a large animal model in the future.

The transplantation of undifferentiated PSCs may result in the formation of teratomas. Thus, it is critical to purify cardiac cells and remove contaminated immature cells from the cardiac grafts to eliminate the risk of tumor formation. Cardiomyocyte-specific gene reporter systems can be used for the high-grade purification of cardiomyocytes, but this method requires genetic modifications. ${ }^{35), 36)}$ Hattori et al. reported that a fluorescent dye that labels mitochondria can be used to selectively mark ESC/iPSC-derived cardiomyocytes. ${ }^{11)}$ They demonstrated that highly pure cardiomyocytes could be obtained by fluorescence-activated cell sorting (FACS) with this dye. Dubois et al. used a surface protein, signal-regulatory protein alpha (SIRPA), as a cardiac-specific marker and purified cardiomyocytes (up to $98 \%$ purity) via FACS. ${ }^{12)}$ Tohyama et al. have reported a simple medium-exchanging procedure that enabled cardiomyocyte purification of up to $99 \%$, based on the marked biochemical differences in glucose and lactate metabolism between cardiomyocytes and noncardiomyocytes. ${ }^{37)}$ 


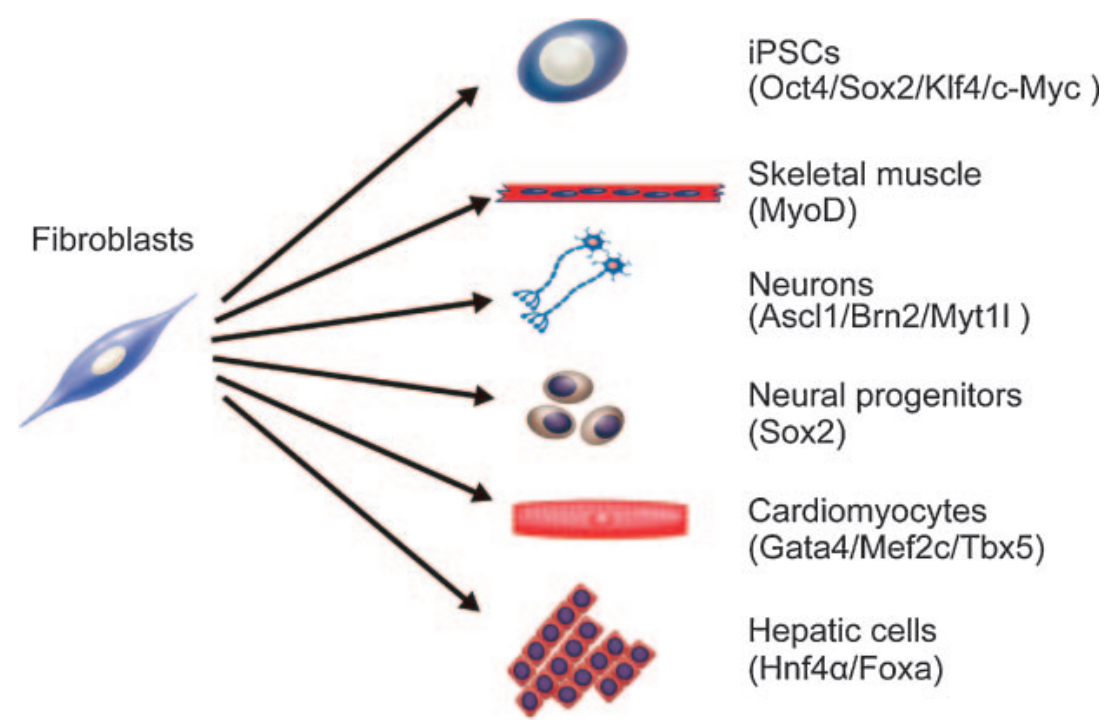

Fig. 2. Overexpression of specific reprogramming factors reprograms fibroblasts into other type of cells. Fibroblasts can be converted into iPSCs, ${ }^{7)}$ skeletal muscle cells ${ }^{38)}$ neurons,${ }^{17)}$ neural progenitors,${ }^{39)}$ cardiomyocytes,${ }^{14)}$ and hepatocytes ${ }^{15)}$ by transduction of lineage-specific transcription factors (parentheses).

Such non-genetic methods might be powerful tools for future clinical applications.

\section{Direct reprogramming of fibroblasts into cardiomyocytes by defined factors}

It is possible to avoid tumor formation by cell therapy, if target cells can be obtained directly from somatic cells without passing through stem cell generation (Fig. 2). ${ }^{14)-17), 29), 38), 39)}$ Zhou et al. reported that the combination of pancreatic transcription factors, Neurogenin 3, Pdx1 and Mafa, can efficiently reprogram pancreatic exocrine cells into functional $\beta$-cells in vivo. ${ }^{18)}$ Vierbuchen et al. reported that neural-specific transcription factors, Ascl1, Brn2 and Myt1l, convert dermal fibroblasts into functional neurons. ${ }^{17)}$ We first found that a minimum cocktail of three cardiac-specific transcription factors, Gata4, Mef2c and Tbx5 (GMT), directly induced cardiomyocyte-like cells from mouse fibroblasts in vitro. ${ }^{14)}$

In our study, we used cardiac fibroblasts (CFs) as a cell source for cardiac reprogramming. CFs are found throughout cardiac tissues along with cardiomyocytes, and account for more than half of the cells in the heart. ${ }^{40)-42)}$ In diseased hearts, fibroblasts proliferate and secrete extracellular matrix and growth factors which induce fibrosis and myocardial remodeling, leading to heart failure ${ }^{43)}$ To determine the candidate factors of cardiac reprogramming, we identified the genes which are specifically expressed in embryonic cardiomyocytes. We developed a novel cell purification system in which embryonic cardiomyocytes and CFs can be purified using FACS. ${ }^{41)}$ Using this system, we selected 14 factors as candidates for cardiac reprogramming, which are specifically expressed in cardiomyocytes and are critical for heart development, demonstrated in knockout mouse studies.

We next developed a screening system in which the induction of mature cardiomyocytes from fibroblasts could be analyzed quantitatively by FACS. We generated $\alpha$ myosin heavy chain $(\alpha \mathrm{MHC})$ promoter-driven EGFP-IRES-Puromycin transgenic mice $(\alpha \mathrm{MHC}-\mathrm{GFP})$, in which only mature cardiomyocytes expressed the green fluorescent protein (GFP). ${ }^{14), 44), 45)}$ Transduction of all 14 factors into fibroblasts induced $1.7 \%$ of $\mathrm{GFP}^{+}$cells, and serial removal of individual factors demonstrated that a combination of three factors (Gata4, Mef2c and Tbx5) were sufficient for efficient $\mathrm{GFP}^{+}$cell induction (around 15\%) from CFs. The three cardiac reprogramming factors, Gata4, Mef2c and Tbx5, are core cardiac transcription factors during early heart development ${ }^{46)-48)}$ and are known to interact with each other, coactivate cardiac gene expression and promote cardiomyocyte differentiation. ${ }^{49)-51)}$ We designated these $\mathrm{GFP}^{+}$cardiomyocyte-like cells induced cardiomyocytes (iCMs). The iCMs expressed several cardiac marker proteins, such as sarcomeric $\alpha$-actinin, cardiac troponin $\mathrm{T}$ and atrial natriuretic 


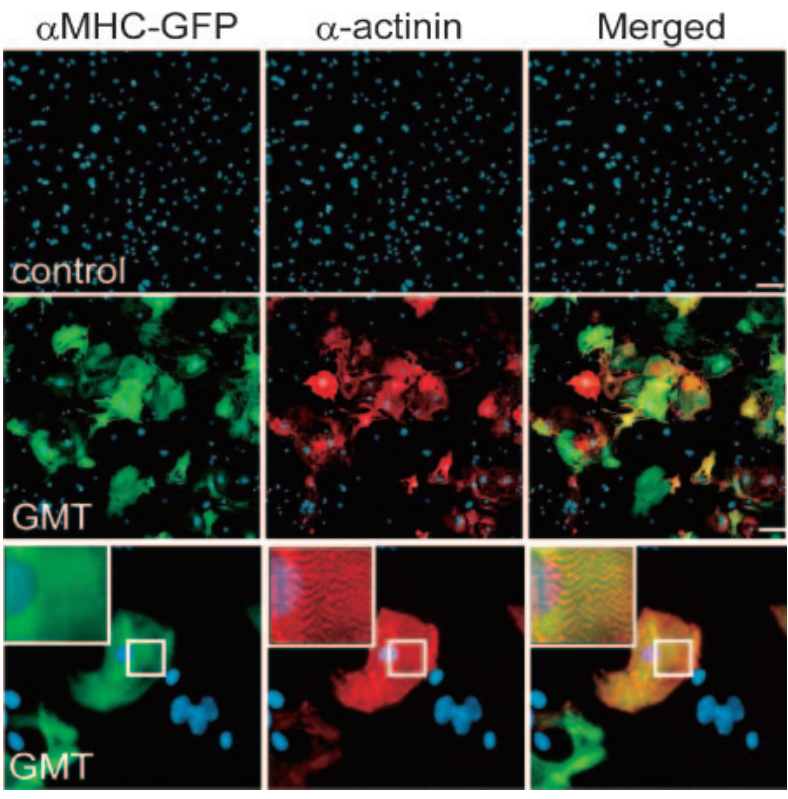

Fig. 3. Gata4/Mef2c/Tbx5 Induce cardiac gene expression in fibroblasts. Immunofluorescent staining for $\alpha \mathrm{MHC}-\mathrm{GFP}$ (green), $\alpha$-actinin (red) and DAPI (blue). In the negative control (control), cardiac genes were not induced. The combination of three factors, Gata4/Mef2c/Tbx5 (GMT), induced abundant $\alpha \mathrm{MHC}-\mathrm{GFP}$ and $\alpha$-actinin expression in fibroblasts. High-magnification views in insets showed sarcomeric organization. ${ }^{14)}$

factor (Fig. 3). They also had well-defined sarcomeric structures similar to neonatal cardiomyocytes. The global gene expression profile of $\mathrm{GFP}^{+} \mathrm{iCMs}$ is not identical but similar to neonatal cardiomyocytes, and different from original CFs (Fig. 4). We also found that functionally important cardiac genes, such as ion channel genes and sarcomere genes were upregulated more in 4 -week iCMs than in 2 -week iCMs, suggesting full maturation occurred over several weeks. The chromatin state of iCMs was also similar to cardiomyocytes but different from fibroblasts in histone modifications and DNA methylation patterns. ${ }^{14)}$ These results suggest that $\mathrm{iCMs}$ are cardiomyocyte-like cells in gene expression and epigenetic states. We also demonstrated that iCMs possessed functional properties which are characteristic of cardiomyocytes. The iCMs exhibited intracellular $\mathrm{Ca}^{2+}$ transient and action potentials after 2-4 weeks of culture. In addition, CF-derived iCMs contracted spontaneously.

To determine if the iCMs could arise from cells in other organs, we transduced the three factors into mouse tail-tip fibroblasts (TTFs). We found that TTF-derived $\mathrm{GFP}^{+}$cells expressed cardiac markers

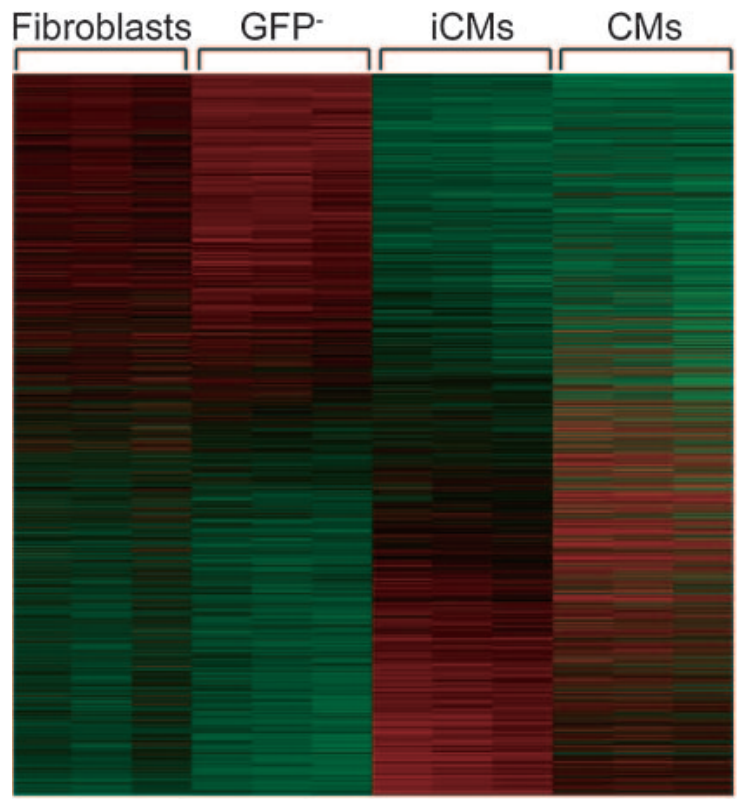

FDR-adj $p<0.0001$ in at least one comparison

Fig. 4. Global gene expression pattern of induced cardiomyocytes is similar to cardiomyocytes. Heatmap image of microarray data illustrating differentially expressed genes among fibroblasts, $\alpha$-MHC-GFP ${ }^{-}$cells $\left(\mathrm{GFP}^{-}\right)$, iCMs $\left(\alpha-\mathrm{MHC}_{-} \mathrm{GFP}^{+}\right.$cells sorted 4 weeks after GMT transduction) and cardiomyocytes ( $\mathrm{CMs})$ $(n=3$ in each group). FDR-adj $\mathrm{p}<0.0001$ in at least one comparison was shown. Global gene expression pattern of iCMs is not identical but similar to cardiomyocytes. ${ }^{14)}$

and spontaneous intracellular $\mathrm{Ca}^{2+}$ transient, while the percentage of cardiac troponin $\mathrm{T}^{+}$cells was $50 \%$ less than that of CF-derived iCMs. The TTF-derived iCMs had some functional characteristics of cardiomyocytes, such as spontaneous intracellular $\mathrm{Ca}^{2+}$ transients, but we did not observe cellular contraction, suggesting that TTFs are more resistant to cardiac reprogramming by GMT. These findings exclude the possibility that iCMs arise from contamination of cardiomyocytes or cardiac progenitors in the fibroblast population. ${ }^{52), 53)}$

While direct conversion of somatic cells to $\beta$-cells and neurons has been reported, the "route" of cell fate alteration is not clear. There are two possibilities for the reprogramming of fibroblasts into differentiated cardiomyocytes. One is a direct conversion of fibroblasts into differentiated cardiomyocytes and the other is that fibroblasts first revert to a cardiac progenitor/stem cell fate before further cardiac differentiation. We were able to genetically test these two possibilities by using the mice expressing Isl1Cre-yellow fluorescent protein (YFP) and Mesp1- 


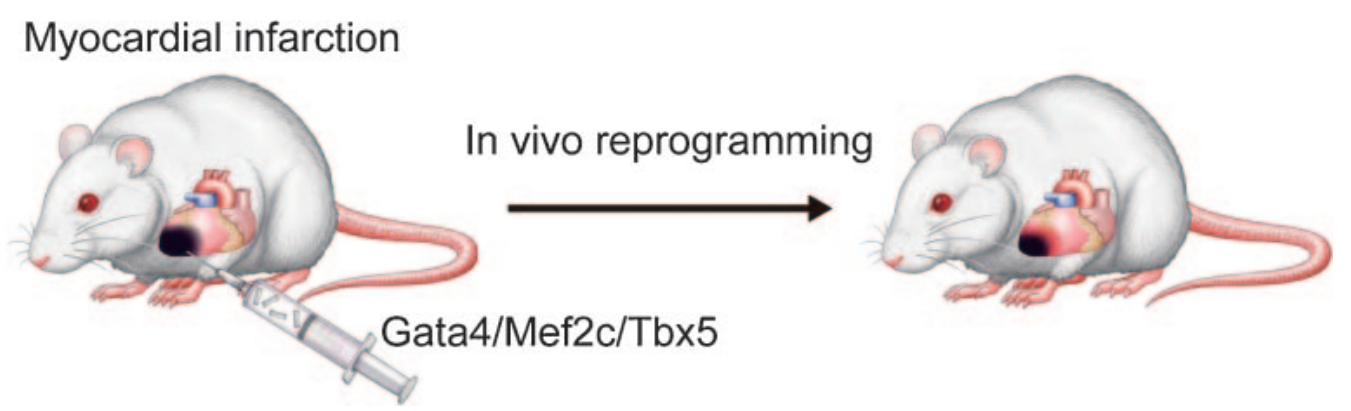

Fig. 5. Gata4/Mef2c/Tbx5 Injection into mouse infarct hearts. Strategy for in vivo cardiac reprogramming by Gata4, Mef2c and Tbx5. Myocardial infarction was generated by coronary artery ligation in mouse. A pool of Gata4, Mef2c and Tbx5 was directly injected into the mouse hearts immediately after coronary artery ligation. Gene transfer of reprogramming factors induced new cardiomyocyte generation in a subset of fibroblasts in infarcted hearts.

Cre-YFP obtained by crossing Isl1-Cre or Mesp1-Cre mice with R26R-EYFP mice. ${ }^{54)}$ Isl1 and Mesp1 are transiently expressed in early cardiac progenitor cells before further cardiac differentiation. ${ }^{25), 55)}$ We found that iCMs induced from Isl1-Cre-YFP and Mesp1Cre-YFP fibroblasts did not express YFP, suggesting the fibroblasts directly reprogrammed into differentiated cardiomyocytes without passing through a cardiac progenitor cell state, with GMT transduction. We next investigated whether GMT-transduced CFs can be transplanted in vivo and be reprogrammed into cardiomyocytes within the heart. CFs infected with GMT expressed $\alpha$-MHC GFP and sarcomeric markers, and converted into cardiomyocyte-like cells in the mouse hearts after 2 weeks of cell transplantation.

Following our initial report, other groups also reported generation of cardiomyocyte-like cells from mouse fibroblasts based on the same factors or microRNAs. Song et al. reported that adding Hand2 to GMT converted adult CFs and TTFs into functional cardiomyocyte-like cells more efficiently than GMT alone. ${ }^{20)}$ Protze et al. found that the combination of Mef2c, Myocardin and Tbx5 upregulated a broad spectrum of cardiac genes and induced functional cardiomyocytes from mouse embryonic fibroblasts and CFs. ${ }^{56)}$ Jayawardena et al. reported that a combination of muscle-specific microRNAs, mir-1, 133, 208 and 499, can convert CFs into functional cardiomyocyte-like cells. ${ }^{57)}$ Thus, both GMT and other combinations of factors can induce cardiac reprogramming, which is similar to the experience in the iPSC field. Although the induction of fully matured cardiac cells remains low in culture and further refinements are needed, these results suggest that large amounts of an individual's own fibroblasts can be transduced with the cardiac reprogramming factors ex vivo and be delivered to damaged myocardium for regenerative purposes.

Induction of cardiomyocyte-like cells in vivo by gene transfer of cardiac reprogramming factors

Based on the findings of direct cardiac reprogramming in vitro, we investigated whether gene transfer of GMT into mouse injured hearts could similarly induce cardiomyocyte generation (Fig. 5). ${ }^{21)}$ We first confirmed that in vitro transduction of GMT retrovirus converted adult cardiac fibroblasts from the mouse infarct region into $\mathrm{iCMs}$ with cardiac-specific gene expression and sarcomeric structures. Injection of GMT retrovirus into $\alpha \mathrm{MHC}$ GFP transgenic mouse hearts induced the expression of $\alpha \mathrm{MHC}-\mathrm{GFP}$, a reporter of cardiomyocytes, in 3\% of virus-infected cells. A mixture of GMT injection into the immunosuppressed mouse hearts induced cardiac protein expression in retrovirus-infected cells within 2 weeks with a conversion rate of approximately $1 \%$, although few cells showed striated muscle structures. Next, to transduce GMT more efficiently in vivo, we developed a polycistronic retrovirus vector expressing GMT separated by $2 \mathrm{~A}$ "self-cleaving" peptides (3F2A). In vivo gene transfer of $3 \mathrm{~F} 2 \mathrm{~A}$ into infarct hearts resulted in generation of induced cardiomyocyte-like cells in fibrotic tissues, which expressed sarcomeric $\alpha$-actinin, cardiac troponin $\mathrm{T}$, and several cardiac-specific genes, and had clear cross striations (Fig. 6). These results suggest that $3 \mathrm{~F} 2 \mathrm{~A}-\mathrm{iCM}$ s were more mature cardiomyocytes and that the polycistronic vector can be used for cellular reprogramming in vivo.

In parallel with us, two other groups also published independently in vivo cardiac reprogramming in mouse infarct hearts. Qian et al. found that non-myocytes in infarcted hearts were converted into 
A

GMT mixture

3F2A

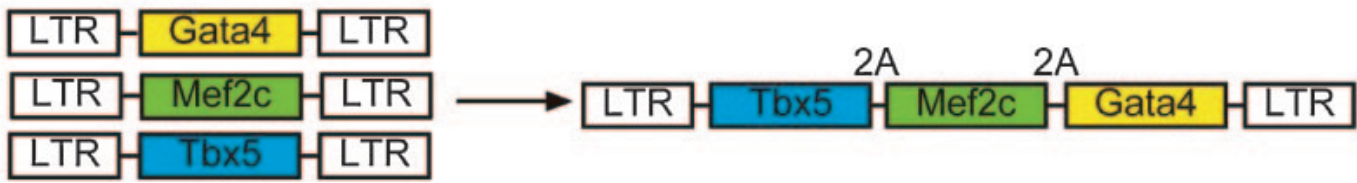

$\mathrm{B}$
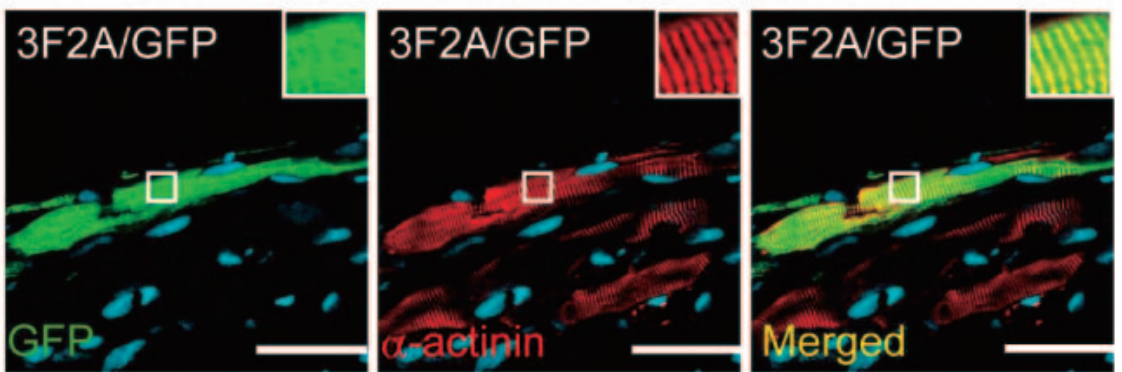

Fig. 6. Induction of cardiomyocyte-like cells in infarct hearts by a single polycistronic vector of Gata4/Mef2c/Tbx5. (A) We developed a polycistronic retrovirus expressing GMT at near equimolar levels from the same promoter using "self-cleaving" $2 \mathrm{~A}$ peptides (3F2A). Schematic representation of the $3 \mathrm{~F} 2 \mathrm{~A}$ retrovirus containing Gata4, Mef2c and Tbx5 (GMT). ${ }^{14)}$ (B) $3 \mathrm{~F} 2 \mathrm{~A}$ retrovirus induced $\alpha$-actinin expression and cross striations. White boxes are enlarged in the insets. ${ }^{14)}$

cardiomyocyte-like cells by GMT retroviral gene transfer. ${ }^{19)}$ Song et al. reported that adding Hand2 to GMT converted CFs into functional cardiomyocyte-like cells more efficiently than GMT alone in vivo. ${ }^{20)}$ Both studies demonstrated that the in vivo iCMs had well-organized sarcomeric structures and exhibited functional characteristics of adult ventricular cardiomyocytes, including cellular contraction, electrophysiological properties and functional coupling to other cardiac cells. They also demonstrated that retroviral gene transfer of reprogramming factors into infarct hearts significantly improved cardiac function and reduced fibrosis 2 and 3 months after myocardial infarction. Although all three studies, including us, demonstrated in vivo cardiac reprogramming, the approaches used to address this issue differ. The other two groups used mainly fibroblast-lineage tracing mice to demonstrate cardiac conversion from CFs, while we took an alternative approach of co-transduction with GMT plus marker genes (GFP or DsRed) to demonstrate cardiac induction in the infarct regions using $\alpha \mathrm{MHC}-\mathrm{GFP}$ transgenic or nude mice. It is possible that the different mouse lines and viral titers used may result in different outcomes among the three studies. Although it is not clear how many newly generated iCMs remained in the injured hearts in the longer-term follow-up and to what extent the iCMs contributed to the improvement in cardiac function, these findings might inform new regenerative strategies for repairing injured hearts. Further works in larger animals, generation of human iCMs and more efficient protocol for direct cardiac reprogramming are needed in the future research.

\section{Conclusions}

The work of numerous laboratories has led to significant therapeutic and scientific advances in stem cell applications to cardiac regenerative medicine. Nevertheless, the issues relating to cardiac differentiation efficiency, risk of tumor formation and the time-consuming steps required to generate a large number of cardiomyocytes through iPSCs need to be solved before clinical applications. The new direct cardiac reprogramming technology, in which target cardiac cells can be generated from fibroblast cells by defined factors without reverting to stem cells, may overcome these issues. ${ }^{14)}$ Although much refinement of the reprogramming procedures will be necessary, this new technology raises the possibility of reprogramming endogenous cardiac fibroblasts into functional cardiomyocytes. Studies in human cells, the safe and efficient delivery system of defined factors in vivo, and an understanding of the molecular mechanisms involved in direct cardiac reprogramming are necessary. A combination of iPSC-based 
cardiomyocyte therapy and direct cardiac reprogramming may facilitate the translation of heart regenerative research into clinical applications in the future.

\section{Acknowledgements}

This study was supported in part by research grants from the JST CREST, JSPS, The Mitsubishi Foundation, AstraZeneca, Takeda Science Foundation, Banyu Life Science, The Uehara Memorial Foundation, Kimura Memorial Heart Foundation, Japan Research Foundation for Clinical Pharmacology, Nateglinide Memorial Toyoshima Research and Education Fund, and SENSHIN Medical Research Foundation.

\section{References}

1) Taylor, D.O., Edwards, L.B., Aurora, P., Christie, J.D., Dobbels, F., Kirk, R., Rahmel, A.O., Kucheryavaya, A.Y. and Hertz, M.I. (2008) Registry of the international society for heart and lung transplantation: Twenty-fifth official adult heart transplant report-2008. J. Heart Lung Transplant. 27, 943-956.

2) Mummery, C., Ward, D., van den Brink, C.E., Bird, S.D., Doevendans, P.A., Opthof, T., Brutel de la Riviere, A., Tertoolen, L., van der Heyden, M. and Pera, M. (2002) Cardiomyocyte differentiation of mouse and human embryonic stem cells. J. Anat. 200, 233-242.

3) Laflamme, M.A., Chen, K.Y., Naumova, A.V., Muskheli, V., Fugate, J.A., Dupras, S.K. Reinecke, H., Xu, C., Hassanipour, M., Police, S., O'Sullivan, C., Collins, L., Chen, Y., Minami, E., Gill, E.A., Ueno, S., Yuan, C., Gold, J. and Murry, C.E. (2007) Cardiomyocytes derived from human embryonic stem cells in pro-survival factors enhance function of infarcted rat hearts. Nat. Biotechnol. 25, 1015-1024.

4) Nussbaum, J., Minami, E., Laflamme, M.A., Virag, J.A., Ware, C.B., Masino, A., Muskheli, V., Pabon, L., Reinecke, H. and Murry, C.E. (2007) Transplantation of undifferentiated murine embryonic stem cells in the heart: Teratoma formation and immune response. FASEB J. 21, 1345-1357.

5) van Laake, L.W., Passier, R., Doevendans, P.A. and Mummery, C.L. (2008) Human embryonic stem cell-derived cardiomyocytes and cardiac repair in rodents. Circ. Res. 102, 1008-1010.

6) Zhang, J., Wilson, G.F., Soerens, A.G., Koonce, C.H., Yu, J., Palecek, S.P., Thomson, J.A. and Kamp, T.J. (2009) Functional cardiomyocytes derived from human induced pluripotent stem cells. Circ. Res. 104, e30-e41.

7) Takahashi, K. and Yamanaka, S. (2006) Induction of pluripotent stem cells from mouse embryonic and adult fibroblast cultures by defined factors. Cell 126, 663-676.

8) Lian, X., Hsiao, C., Wilson, G., Zhu, K., Hazeltine,
L.B., Azarin, S.M., Raval, K.K., Zhang, J., Kamp, T.J. and Palecek, S.P. (2012) Robust cardiomyocyte differentiation from human pluripotent stem cells via temporal modulation of canonical wnt signaling. Proc. Natl. Acad. Sci. U.S.A. 109, E1848-E1857.

9) Kattman, S.J., Witty, A.D., Gagliardi, M., Dubois, N.C., Niapour, M., Hotta, A., Ellis, J. and Keller, G. (2011) Stage-specific optimization of activin/ nodal and bmp signaling promotes cardiac differentiation of mouse and human pluripotent stem cell lines. Cell Stem Cell 8, 228-240.

10) Uosaki, H., Fukushima, H., Takeuchi, A., Matsuoka, S., Nakatsuji, N., Yamanaka, S. and Yamashita, J.K. (2011) Efficient and scalable purification of cardiomyocytes from human embryonic and induced pluripotent stem cells by vcam1 surface expression. PLoS ONE 6, e23657.

11) Hattori, F., Chen, H., Yamashita, H., Tohyama, S., Satoh, Y.S., Yuasa, S., Li, W., Yamakawa, H., Tanaka, T., Onitsuka, T., Shimoji, K., Ohno, Y., Egashira, T., Kaneda, R., Murata, M., Hidaka, K., Morisaki, T., Sasaki, E., Suzuki, T., Sano, M., Makino, S., Oikawa, S. and Fukuda, K. (2010) Nongenetic method for purifying stem cell-derived cardiomyocytes. Nat. Methods 7, 61-66.

12) Dubois, N.C., Craft, A.M., Sharma, P., Elliott, D.A., Stanley, E.G., Elefanty, A.G., Gramolini, A. and Keller, G. (2011) Sirpa is a specific cell-surface marker for isolating cardiomyocytes derived from human pluripotent stem cells. Nat. Biotechnol. 29, 1011-1018.

13) Shiba, Y., Fernandes, S., Zhu, W.Z., Filice, D., Muskheli, V., Kim, J., Palpant, N.J., Gantz, J., Moyes, K.W., Reinecke, H., Van Biber, B., Dardas, T., Mignone, J.L., Izawa, A., Hanna, R., Viswanathan, M., Gold, J.D., Kotlikoff, M.I., Sarvazyan, N., Kay, M.W., Murry, C.E. and Laflamme, M.A. (2012) Human ES-cell-derived cardiomyocytes electrically couple and suppress arrhythmias in injured hearts. Nature 489, 322325.

14) Ieda, M., Fu, J.D., Delgado-Olguin, P., Vedantham, V., Hayashi, Y., Bruneau, B.G. and Srivastava, D. (2010) Direct reprogramming of fibroblasts into functional cardiomyocytes by defined factors. Cell 142, 375-386.

15) Sekiya, S. and Suzuki, A. (2011) Direct conversion of mouse fibroblasts to hepatocyte-like cells by defined factors. Nature 475, 390-393.

16) Pang, Z.P., Yang, N., Vierbuchen, T., Ostermeier, A., Fuentes, D.R., Yang, T.Q., Citri, A. Sebastiano, V., Marro, S., Sudhof, T.C. and Wernig, M. (2011) Induction of human neuronal cells by defined transcription factors. Nature $\mathbf{4 7 6}$, 220-223.

17) Vierbuchen, T., Ostermeier, A., Pang, Z.P., Kokubu, Y., Sudhof, T.C. and Wernig, M. (2010) Direct conversion of fibroblasts to functional neurons by defined factors. Nature 463, 1035-1041.

18) Zhou, Q., Brown, J., Kanarek, A., Rajagopal, J. and Melton, D.A. (2008) In vivo reprogramming of 
adult pancreatic exocrine cells to $\beta$-cells. Nature 455, 627-632.

19) Qian, L., Huang, Y., Spencer, C.I., Foley, A., Vedantham, V., Liu, L., Conway, S.J., Fu, J.D. and Srivastava, D. (2012) In vivo reprogramming of murine cardiac fibroblasts into induced cardiomyocytes. Nature 485, 593-598.

20) Song, K., Nam, Y.J., Luo, X., Qi, X., Tan, W., Huang, G.N., Acharya, A., Smith, C.L., Tallquist, M.D., Neilson, E.G., Hill, J.A., Bassel-Duby, R. and Olson, E.N. (2012) Heart repair by reprogramming non-myocytes with cardiac transcription factors. Nature 485, 599-604.

21) Inagawa, K., Miyamoto, K., Yamakawa, H., Muraoka, N., Sadahiro, T., Umei, T., Wada, R., Katsumata, Y., Kaneda, R., Nakade, K., Kurihara, C., Obata, Y., Miyake, K., Fukuda, K. and Ieda, M. (2012) Induction of cardiomyocyte-like cells in infarct hearts by gene transfer of Gata4, Mef2c, and Tbx5. Circ. Res. 111, 1147-1156.

22) Kattman, S.J., Huber, T.L. and Keller, G.M. (2006) Multipotent $\mathrm{flk}-1^{+}$cardiovascular progenitor cells give rise to the cardiomyocyte, endothelial, and vascular smooth muscle lineages. Dev. Cell 11, 723-732.

23) Qyang, Y., Martin-Puig, S., Chiravuri, M., Chen, S., $\mathrm{Xu}, \mathrm{H} ., \mathrm{Bu}$, L., Jiang, X., Lin, L., Granger, A., Moretti, A., Caron, L., Wu, X., Clarke, J., Taketo, M.M., Laugwitz, K.L., Moon, R.T., Gruber, P., Evans, S.M., Ding, S. and Chien, K.R. (2007) The renewal and differentiation of $i s l 1^{+}$cardiovascular progenitors are controlled by a wnt/ $\beta$-catenin pathway. Cell Stem Cell 1, 165-179.

24) Wu, S.M., Fujiwara, Y., Cibulsky, S.M., Clapham, D.E., Lien, C.L., Schultheiss, T.M. and Orkin, S.H. (2006) Developmental origin of a bipotential myocardial and smooth muscle cell precursor in the mammalian heart. Cell 127, 1137-1150.

25) Bondue, A., Lapouge, G., Paulissen, C., Semeraro, C., Iacovino, M., Kyba, M. and Blanpain, C. (2008) Mesp1 acts as a master regulator of multipotent cardiovascular progenitor specification. Cell Stem Cell 3, 69-84.

26) David, R., Brenner, C., Stieber, J., Schwarz, F., Brunner, S., Vollmer, M., Mentele, E., MullerHocker, J., Kitajima, S., Lickert, H., Rupp, R. and Franz, W.M. (2008) MesP1 drives vertebrate cardiovascular differentiation through Dkk-1mediated blockade of Wnt-signalling. Nat. Cell Biol. 10, 338-345.

27) Lindsley, R.C., Gill, J.G., Murphy, T.L., Langer, E.M., Cai, M., Mashayekhi, M., Wang, W., Niwa, N., Nerbonne, J.M., Kyba, M. and Murphy, K.M. (2008) Mesp1 coordinately regulates cardiovascular fate restriction and epithelial-mesenchymal transition in differentiating ESCs. Cell Stem Cell 3, 55-68.

28) Yu, J., Vodyanik, M.A., Smuga-Otto, K., Antosiewicz-Bourget, J., Frane, J.L., Tian, S., Nie, J., Jonsdottir, G.A., Ruotti, V., Stewart, R. Slukvin, I.I. and Thomson, J.A. (2007) Induced pluripotent stem cell lines derived from human somatic cells. Science 318, 1917-1920.

29) Takahashi, K., Tanabe, K., Ohnuki, M., Narita, M., Ichisaka, T., Tomoda, K. and Yamanaka, S. (2007) Induction of pluripotent stem cells from adult human fibroblasts by defined factors. Cell 131, 861-872.

30) Okita, K. and Yamanaka, S. (2010) Induction of pluripotency by defined factors. Exp. Cell Res. 316, 2565-2570.

31) Seki, T., Yuasa, S., Oda, M., Egashira, T., Yae, K., Kusumoto, D., Nakata, H., Tohyama, S., Hashimoto, H., Kodaira, M., Okada, Y., Seimiya, H., Fusaki, N., Hasegawa, M. and Fukuda, K. (2010) Generation of induced pluripotent stem cells from human terminally differentiated circulating T cells. Cell Stem Cell 7, 11-14.

32) Tiscornia, G., Monserrat, N. and Belmonte, J.C. (2011) Modelling long QT syndrome with iPS cells: Be still, my beating heart... Circ. Res. 108, 648649.

33) Tsuji, O., Miura, K., Okada, Y., Fujiyoshi, K., Mukaino, M., Nagoshi, N., Kitamura, K., Kumagai, G., Nishino, M., Tomisato, S., Higashi, H., Nagai, T., Katoh, H., Kohda, K., Matsuzaki, Y., Yuzaki, M., Ikeda, E., Toyama, Y., Nakamura, M., Yamanaka, S. and Okano, H. (2010) Therapeutic potential of appropriately evaluated safeinduced pluripotent stem cells for spinal cord injury. Proc. Natl. Acad. Sci. U.S.A. 107, 1270412709 .

34) Zhang, M., Methot, D., Poppa, V., Fujio, Y., Walsh, K. and Murry, C.E. (2001) Cardiomyocyte grafting for cardiac repair: Graft cell death and anti-death strategies. J. Mol. Cell. Cardiol. 33, 907-921.

35) Caspi, O., Huber, I., Kehat, I., Habib, M., Arbel, G., Gepstein, A., Yankelson, L., Aronson, D., Beyar, R. and Gepstein, L. (2007) Transplantation of human embryonic stem cell-derived cardiomyocytes improves myocardial performance in infarcted rat hearts. J. Am. Coll. Cardiol. 50, 1884-1893.

36) Huber, I., Itzhaki, I., Caspi, O., Arbel, G., Tzukerman, M., Gepstein, A., Habib, M., Yankelson, L., Kehat, I. and Gepstein, L. (2007) Identification and selection of cardiomyocytes during human embryonic stem cell differentiation. FASEB J. 21, 2551-2563.

37) Tohyama, S., Hattori, F., Sano, M., Hishiki, T., Nagahata, Y., Matsuura, T., Hashimoto, H., Suzuki, T., Yamashita, H., Satoh, Y., Egashira, T., Seki, T., Muraoka, N., Yamakawa, H., Ohgino, Y., Tanaka, T., Yoichi, M., Yuasa, S., Murata, M., Suematsu, M. and Fukuda, K. (2013) Distinct metabolic flow enables large-scale purification of mouse and human pluripotent stem cell-derived cardiomyocytes. Cell Stem Cell 12, 127-137.

38) Davis, R.L., Weintraub, H. and Lassar, A.B. (1987) Expression of a single transfected cDNA converts fibroblasts to myoblasts. Cell 51, 987-1000.

39) Ring, K.L., Tong, L.M., Balestra, M.E., Javier, R., Andrews-Zwilling, Y., Li, G., Walker, D., Zhang, W.R., Kreitzer, A.C. and Huang, Y. (2012) Direct 
reprogramming of mouse and human fibroblasts into multipotent neural stem cells with a single factor. Cell Stem Cell 11, 100-109.

40) Baudino, T.A., Carver, W., Giles, W. and Borg, T.K. (2006) Cardiac fibroblasts: Friend or foe? Am. J. Physiol. Heart Circ. Physiol. 291, H1015-H1026.

41) Ieda, M., Tsuchihashi, T., Ivey, K.N., Ross, R.S., Hong, T.T., Shaw, R.M. and Srivastava, D. (2009) Cardiac fibroblasts regulate myocardial proliferation through $\beta 1$ integrin signaling. Dev. Cell 16, 233-244.

42) Camelliti, P., Borg, T.K. and Kohl, P. (2005) Structural and functional characterisation of cardiac fibroblasts. Cardiovasc. Res. 65, 40-51.

43) Weber, K.T. and Brilla, C.G. (1991) Pathological hypertrophy and cardiac interstitium. Fibrosis and renin-angiotensin-aldosterone system. Circulation 83, 1849-1865.

44) Ieda, M., Kanazawa, H., Kimura, K., Hattori, F., Ieda, Y., Taniguchi, M., Lee, J.K., Matsumura, K., Tomita, Y., Miyoshi, S., Shimoda, K., Makino, S., Sano, M., Kodama, I., Ogawa, S. and Fukuda, K. (2007) Sema3a maintains normal heart rhythm through sympathetic innervation patterning. Nat. Med. 13, 604-612.

45) Gulick, J., Subramaniam, A., Neumann, J. and Robbins, J. (1991) Isolation and characterization of the mouse cardiac myosin heavy chain genes. J. Biol. Chem. 266, 9180-9185.

46) Zhao, R., Watt, A.J., Battle, M.A., Li, J., Bondow, B.J. and Duncan, S.A. (2008) Loss of both GATA4 and GATA 6 blocks cardiac myocyte differentiation and results in acardia in mice. Dev. Biol. 317, 614-619.

47) Srivastava, D. (2006) Making or breaking the heart: From lineage determination to morphogenesis. Cell 126, 1037-1048.

48) Olson, E.N. (2006) Gene regulatory networks in the evolution and development of the heart. Science 313, 1922-1927.

49) Ghosh, T.K., Song, F.F., Packham, E.A., Buxton, S., Robinson, T.E., Ronksley, J., Self, T., Bonser, A.J. and Brook, J.D. (2009) Physical interaction between TBX5 and MEF2C is required for early heart development. Mol. Cell. Biol. 29, 2205-2218.

50) Garg, V., Kathiriya, I.S., Barnes, R., Schluterman,
M.K., King, I.N., Butler, C.A., Rothrock, C.R., Eapen, R.S., Hirayama-Yamada, K., Joo, K., Matsuoka, R., Cohen, J.C. and Srivastava, D. (2003) GATA4 mutations cause human congenital heart defects and reveal an interaction with TBX5. Nature 424, 443-447.

51) Morin, S., Charron, F., Robitaille, L. and Nemer, M. (2000) GATA-dependent recruitment of MEF2 proteins to target promoters. EMBO J. 19, 20462055.

52) Andersen, D.C., Andersen, P., Schneider, M., Jensen, H.B. and Sheikh, S.P. (2009) Murine "cardiospheres" are not a source of stem cells with cardiomyogenic potential. Stem Cells 27, 15711581.

53) Davis, D.R., Zhang, Y., Smith, R.R., Cheng, K., Terrovitis, J., Malliaras, K., Li, T.S., White, A., Makkar, R. and Marban, E. (2009) Validation of the cardiosphere method to culture cardiac progenitor cells from myocardial tissue. PLoS ONE 4, e7195.

54) Srinivas, S., Watanabe, T., Lin, C.S., William, C.M., Tanabe, Y., Jessell, T.M. and Costantini, F. (2001) Cre reporter strains produced by targeted insertion of EYFP and ECFP into the ROSA26 locus. BMC Dev. Biol. 1, 4.

55) Laugwitz, K.L., Moretti, A., Lam, J., Gruber, P., Chen, Y., Woodard, S., Lin, L.Z., Cai, C.L., Lu, M.M., Reth, M., Platoshyn, O., Yuan, J.X., Evans, S. and Chien, K.R. (2005) Postnatal isl1 ${ }^{+}$cardioblasts enter fully differentiated cardiomyocyte lineages. Nature 433, 647-653.

56) Protze, S., Khattak, S., Poulet, C., Lindemann, D., Tanaka, E.M. and Ravens, U. (2012) A new approach to transcription factor screening for reprogramming of fibroblasts to cardiomyocytelike cells. J. Mol. Cell. Cardiol. 53, 323-332.

57) Jayawardena, T.M., Egemnazarov, B., Finch, E.A., Zhang, L., Payne, J.A., Pandya, K., Zhang, Z., Rosenberg, P., Mirotsou, M. and Dzau, V.J. (2012) MicroRNA-mediated in vitro and in vivo direct reprogramming of cardiac fibroblasts to cardiomyocytes. Circ. Res. 110, 1465-1473.

(Received Dec. 4, 2012; accepted Jan. 17, 2013) 


\section{Profile}

Masaki Ieda was born in 1971 and graduated from Keio University School of Medicine in 1995 to obtain M.D. He performed residency and worked as a medical staff in Internal Medicine, Keio University School of Medicine (1995-1999). He received Ph.D. from Keio University School of Medicine in 2005 for the study of the molecular mechanisms of heart development and disease under the direction of Prof. Satoshi Ogawa and Keiichi Fukuda. Dr. Ieda was an instructor in Keio University School of Medicine and continued his research (2005-2007). He moved to the Gladstone Institute of Cardiovascular Disease, University of California, San Francisco, U.S.A., as a Postdoctoral Fellow (2007-2009), and was promoted to be a research scientist in the same institute (2009-2010). After coming back to Japan, he was promoted to the

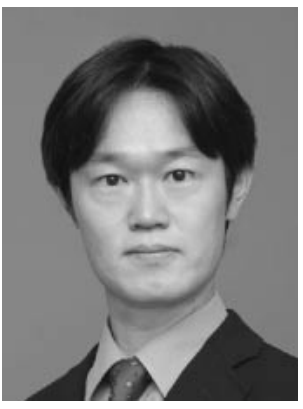
Research Director in Japan Science and Technology Agency (JST), Core Research of Evolutional Science \& Technology (CREST), and the Project Assistant Professor in Keio University School of Medicine. He performed a pioneering work in direct reprogramming, which is altering one mature cell type into another without first becoming stem cells. He demonstrated that overexpression of three cardiac-specific transcription factors, Gata4, Mef2c and Tbx5, induced cardiomyocyte-like cells from mouse fibroblasts in vitro (Ieda et al. (2010) Direct reprogramming of fibroblasts into functional cardiomyocytes by defined factors. Cell. 142, 375-386). This is the first demonstration of generating cardiomyocytes from non-myocytes by defined factors and has brought a tremendous amount of excitement about the possibility of using direct reprogramming technology in regenerative medicine. Subsequently, he and other researchers conducted in vivo direct cardiac reprograming to regenerate mouse ischemic hearts (Refs. 19-21). He was awarded Young Investigator's Award (2006), Yagi's Award (2007), Cardiovascular Regeneration Medical Science Award (2011) from Japanese Circulation Society, and Louis N. \& Arnold M. Katz Young Investigator Award (2008) from American Heart Association. He was given the Medical Research Encouragement Prize from The Japan Medical Association in 2011, and the JSPS PRIZE from JSPS for his study in the Mechanisms of Heart Development and Regeneration in 2012. He is now working in Keio University School of Medicine as the Project Assistant Professor, and in JST CREST as the Research Director. 